\title{
Volume change behavior of bentonite-sand mixture under constant suction condition
}

\author{
Yasir Al-Badran, ${ }^{1, *}$ and Tom Schanz ${ }^{1}$ \\ ${ }^{1}$ Faculty of Civil and Environment Engineering, Ruhr-Universität Bochum, Germany
}

\begin{abstract}
The unsaturated state of soil can raise many geotechnical problems upon wetting-drying cycles such as volume change resulting in collapse or swell, change in the shear strength, and change in the hydraulic conductivity. The classical principles of soil mechanics for saturated soil are often not suitable for explaining these phenomena. An experimental work was carried out to study the volume change behavior of Bentonite-Sand mixture under constant suction condition. A mixture of 30\% Calcigel bentonite and $70 \%$ Haider sand (30B) were tested in this study. The applied suction was kept constant through the tests. Thirteen 30B specimens were tested under constant suction condition. Two different initial states (slurry and loose) were chosen to examine the effect of initial state on the volume change at unsaturated state. The results of first group (initially slurry state) show that once the suction was applied the compressibility of the specimens in this group followed the isotropic NCL up to $255 \mathrm{kPa}$ suction. Subsequently, the slope of compression curve decreased. The results of increasing suction for initially slurry state show that the slope of compression lines became near to zero for suction higher than $600 \mathrm{kPa}$. Moreover, when applied suction is lower than the air-entry value, $s_{a e v}$, the soil behaviors as the saturated soil. Therefore, the effective stress equation can be applied. The results of second group (initially loose state) show that the unsaturated preconsolidation pressure increases as the constant suction increases. The slopes of the unsaturated over consolidated paths in all tests were closed to the slope of saturated over consolidated path $\left(C_{r}\right)$, while the slopes of the unsaturated normal consolidated (yield) state are higher than the slope of saturated NCL. Finally the results show that the slope of the unsaturated NCL is higher (steeper) than the slope of saturated NCL.
\end{abstract}

\section{Introduction}

The soil forming in shallow layers in the arid and semiarid regions and the compacted soil used in earth dams, highways, embankments, airport runways, and the sealing and buffer materials engineering barriers e.g., used for the nuclear repository are in unsaturated conditions. Whenever the water interacts with a soil that is in a state of unsaturated condition volume change may occur. In nuclear (or radioactive) and high-level toxic waste disposal repositories, temperature of the waste elevates due to radioactivity processes which causes drying of the soil and alters the degree of saturation of the soil. The safe disposal of high-level radioactive nuclear waste generated from nuclear power plants is of great concern in many countries due to nuclear waste long-term (at least 10,000 years) detrimental impact on humans if released into the environment. In many countries, the chosen emplacement depth for the waste repositories has been found to vary between 500 to 1000 m (e. g., [1] and [2]). A geologic disposal facility generally consists of metallic canisters containing the radioactive nuclear wastes, buffer materials between the waste canister and bedrock, and backfill materials that would fill the spaces in the excavated access tunnels and pits. The basic functions of the barrier materials used in the waste repositories require a very low hydraulic conductivity in order to provide long-term stability to the barrier system under the high overburden pressure, and the materials should possess a high radionuclide adsorption capacity and a high heat transfer capacity [3]. Therefore, it is important to investigate the materials that have been proposed (such as bentonite-sand mixtures) as these materials are to be used as sealing and buffer elements for the repository beside the studies performed on the host rock site characterization.

The unsaturated condition of the repository induces hydro-mechanical processes of its buffer materials engineering barriers. To precisely understand this behavior the volume change behavior of bentonite-sand mixture under constant suction condition should be investigated. The volume change behavior in this study

\footnotetext{
Corresponding author: husn_irq@yahoo.com
} 
represents the compression curves of bentonite-sand mixtures under constant suction condition. Two initial states are chosen: slurry and loose density state for each soil mixture.

\section{Materials used and samples preparation}

The materials used in this study are pure bentonite 100B and a mixture of bentonite and quartz sand, 30\% bentonite and $70 \%$ sand mixture $30 \mathrm{~B}$. The bentonite and sand mixture' with compositions of 30B was prepared. The bentonite was mined from Bavaria, Southern part of Germany. Table (1) summarizes the properties of bentonite and sand used in this study based on ASTM standards, ASTM (1997) and DIN standards, DIN (1987). The Liquid limit for (30B) mixture is $30 \%$. The slurry soil was prepared by mixing the soil with water equal to 1.2 of liquid limit (L.L.).

To cover all the possible states of unsaturated volume change, the initial conditions of the specimens used are divided into two states: ((i) Slurry (Sl) when drying path was applied and (ii) Loose (Lo) when wetting path was applied. The initial slurry state was used to study the unsaturated volume change of drying path, whereas the initially loose state was used to study the unsaturated volume change of wetting path. The slurry specimens were prepared by mixing the soil with water content equal to 1.2 times its liquid limit (i.e., $36 \%$ for $30 \mathrm{~B}$ ). The soil was mixed daily for at least one week to produce homogenous mixture. The loose specimens were prepared to produce maximum void ratio of unsaturated state. Water content of range $(65 \%-10 \%)$ to achieve suction ranges (12 $\mathrm{MPa}-3.5 \mathrm{MPa})$ brings into being maximum initial void ratio for $30 \mathrm{~B}$ soil.

Table1. Summary of soil properties for materials used, 30B soil.

\begin{tabular}{|c|c|}
\hline Properties of soils & 30B \\
\hline Specific gravity & 2.695 \\
\hline Liquid limit (\%) & 30 \\
\hline Plastic limit (\%) & - \\
\hline Plasticity index (\%) & - \\
\hline Shrinkage limit (\%) & - \\
\hline Clay content (\%) & 8.1 \\
\hline Fine content $(\%)$ & 28.5 \\
\hline $\begin{array}{l}\text { Total specific surface area } \\
\qquad\left(\mathrm{m}^{2} / \mathrm{g}\right)^{*}\end{array}$ & 120 \\
\hline
\end{tabular}

\section{Experimental program}

The study amides to investigate the effect of suction on volumetric yielding behavior under different initial conditions for fine-grained soils. Therefore, the net stress is increased through the test while the suction is kept constant. Thirteen 30B specimens were tested under constant suction condition. The initial states for constant net stress test and the stress paths for each test in (net stress-suction) space are shown in Table (2) and Figure (1), respectively. The following nomenclatures will be used as abbreviation in this work for the mixture percent, type of test, initial condition (e.g. 30B-S39-Sl = 30B mixture with $39000 \mathrm{kPa}$ constant suction test for slurry initial condition): $\mathbf{3 0 B}=30 \%$ bentonite (calcigel) and $70 \%$ sand; $\mathbf{S X}=$ constant suction test of $\mathbf{X ~ M P a ; ~} \mathbf{L o}=$ loose initial state; $\mathbf{S I}=$ slurry initial state.

The tests 30B-S0.1-SL, 30B-S0.45-S1, 30B-S0.05-Lo, and 30B-S0.1-Lo1 were loaded under constant suction condition then followed by wetting process (reduction in suction under constant net stress) at $0.91 \mathrm{MPa}, 1.6 \mathrm{MPa}$, $0.92 \mathrm{MPa}$, and $0.925 \mathrm{MPa}$, respectively. The maximum constant applied suction in the cerise was $39000 \mathrm{kPa}$ (30B-S39-S1 test) because of the possibility to increase the preconsolidation pressure (yield stress) more than $24000 \mathrm{kPa}$ (the maximum limit of the used equipment).

The state of the applied net stress in study is mainly onedimensional using; the modified controlled-suction oedometer cells, UPC-Barcelona cell, UPC-Isochoric cell, and high stress oedometer cell, in the soil laboratory of Ruhr-Universität, Bochum, Germany. All these cells have a specimen with the following dimensions: $50 \mathrm{~mm}$ diameter and $20 \mathrm{~mm}$ height. Only one test for each soil was carried out by applying isotropic stress using triaxial device to locate the position of isotropic normal consolidation line (iso-NCL). The specimen has dimensions $50 \mathrm{~mm}$ diameter and $40 \mathrm{~mm}$ height. The procedure followed for each test depends on the type of the test. Based on the pressure-deformation characteristic of all devices, the measured volume (i.e., dry density and void ratio) at each loading and unloading steps during the compression tests were corrected. The axis translation technique (ATT) and vapor equilibrium technique (VET) were used to apply (control) suction in the used one-dimensional compression cells. For suction range less than $1500 \mathrm{kPa}$, the axis-translation technique (ATT) was used, while for suction higher than $2000 \mathrm{kPa}$, the vapor equilibrium technique (VET) was adopted.

\section{Experimental results and discussion}

The results of the volume change test under constant suction condition are presented in this section. Thirteen 30B specimens ( 8 specimens for initially slurry state and 5 specimens for initially loose state) were tested under constant suction condition. Two different initial states were chosen to examine the effect of initial state (slurry and loose) on the volumetric yielding at unsaturated state. The initial states for constant suction test and the stress paths for each test in (net stress-suction) space are shown in Table (2) and Figure (1), respectively. The initial point is denoted as point $\mathrm{A}$, whereas point $\mathrm{B}$ represents the beginning of applying suction. Point $\mathrm{C}$ represents the beginning of loading under constant suction condition, and point D represents the end of constant suction condition. In the Figures (2 and 14-16.), the applied constant suction was equal to the initial suction, therefore $\mathrm{A}, \mathrm{B}$, and $\mathrm{C}$ correspond to the same 
point. Figures (5.23 and 5.39) were tested under zero suction condition (consolidation test).

Figures (2-11) show the results of first group (initially slurry state) of constant suction test for $30 \mathrm{~B}$ soil. Within these tests, all the specimens start at slurry condition (point A) then the suction increases under seated load (4$7 \mathrm{kPa}$ ), (point $\mathrm{B}$ ), till reaching a specific suction value (point $\mathrm{C}$ ). Beyond that the net stress increases under constant suction condition.

The preconsolidation pressure are 7, 200, 300, 400, 600, 800,1000 , and $8000 \mathrm{kPa}$ under $0,50,100,255,300$, 400,450 , and $39000 \mathrm{kPa}$ constant suction conditions respectively as shown in Figures (2a-10a). The increase in the preconsolidation pressure is due to (i) increase in the density before loading (as result of increasing the applied suction) and (ii) hardening of soil material as a result of increase in suction. Most of curves in this group (except 30B-S39-S1 test) joined the 1D-NCL as net stress increases. This behavior is attributed to increase in the degree of saturation during the loading that made the specimens reaching the saturation zone. The preconsolidation pressures, for tests with constant suction range from 0 to $450 \mathrm{kPa}$, locate on the saturated $1 \mathrm{D}-\mathrm{NCL}$ and the values of these pressures increase as a result of increasing the density due to applying the suction. Note the values of the void ratio before start loading, Figures (2b-10b). The compression curve of 30B-S39-Sl test (Figure 8a.30a) had undergone a high reduction in volume during the initial part of loading (between point $\mathrm{C}$ and $100 \mathrm{kPa}$ net stress). This behavior can be attributed to separation of the sample from the confining ring due to high applied suction $(39000 \mathrm{kPa})$ and the incremental response of the sample changes from oedometric to uniaxial. Therefore, initially the sample had high reduction in volume until it retain back, by filling the space between the sample and the ring with soil material due to lateral deformation, to the oedometric loading condition. As the loading increased the compression curve passed the 1D-NCL till reaching $8000 \mathrm{kPa}$ net stress. Beyond this point the state of the specimen changes from over consolidated to normal consolidated (yield) state with slope higher than the slope of saturated NCL. Once the suction was applied (after point B), the compressibility of the specimens in this group followed the isotropic NCL up to $255 \mathrm{kPa}$ suction. Subsequently, the slope of compression curve decreased. The results of increasing suction for initially slurry show that the slope of compression lines became near to zero (no compression with increasing the suction) for suction higher than $600 \mathrm{kPa}$. The same behavior was observed in case of 30B-S39-Sl test.

The gravimetric water content, of constant suction tests for initially slurry sate, decreased as suction increased along with drying path of SWCC, Figures (3c-10c). The gravimetric water content decreased slightly as the net stress increased for over consolidation (before the preconsolidation pressure). The reduction in the gravimetric water content during the loading at the over consolidated state is believed to be due to change of the state from drying path (due to increasing the suction before loading) to wetting path (due to increase in the degree of saturation as a results of compression the specimen during loading). The results of controlledsuction collapse tests carried out by Sun et al. (2007) showed similar behavior during the over consolidated state. Beyond the preconsolidation pressure it seems to be that the gravimetric water content-suction relationship depends on the degree of saturation. If the degree of saturation is equal or higher than the degree of saturation at air-entry value (about 0.85 for $30 \mathrm{~B}$ soil), as the case of $0,25,100$, and $255 \mathrm{kPa}$ constant suction conditions, the gravimetric water content decreased as net stress increased to keep the specimen in saturated zone. Whereas in case that the degree of saturation was moderately lower than the degree of saturation at airentry value, as the case of 300,400 , and $450 \mathrm{kPa}$ constant suction conditions, the gravimetric water content increased slightly as net stress increased till the degree of saturation reaches value around 0.85 (the degree of saturation at air-entry value), then the relationship followed similar behavior of first case. The third case is when the degree of saturation was significantly lower than the degree of saturation at airentry value, as the case of 30B-S39-S1 test under constant suction of $39000 \mathrm{kPa}$. In this case the results show that the gravimetric water content remained unchanged regardless of increasing the density due to loading. Generally, the degree of saturation decreases with increasing the suction, then increases as the net stress increases, Figures (3d-10d).

For the initially slurry specimens under values for constant suction up to $255 \mathrm{kPa}$, the specimens remain in saturated state (except one point before loading in the 30B-S0.255-Sl test). The soil before the air-entry value, $s_{a e v}$, is in the saturated zone and its behavior as the saturated soil. Therefore, the effective stress (Eq. (1) with $\chi=1$ ) can be applied for void ratio and gravimetric water content, Figure (11). In other tests, the effective stress can be applied for range of suction before air-entry value $(80 \mathrm{kPa})$ only.

$$
\sigma^{\prime}=\left(\sigma-u_{a}\right)+\chi\left(u_{a}-u_{w}\right)
$$

where $\sigma^{\prime}=$ effective stress; $\sigma=$ total stress; $u_{a}=$ pore air pressure; $u_{w}=$ pore water pressure; $\chi=$ effective stress parameter, which has a value of 1 for saturated soils and 0 for dry soils.

Figures (12-17) show the results of second group of tests under constant suction condition for 30B soil: namely the initially loose state. The preconsolidation pressures are 5, 4, 100, 150, and $800 \mathrm{kPa}$ under 50, 100, 4300, 10000 , and $39000 \mathrm{kPa}$ constant suction conditions respectively, Figures (12a-17a). The values of the void ratios in this group before loading (points $C$ 's) was 1.0, $1.1,1.44,1.05$, and 1.05 under 50,100, 4300, 10000, and $39000 \mathrm{kPa}$ constant suction conditions respectively. These values can give some explanations about the relationship between the initial void ratio (initial density) and the unsaturated preconsolidation pressure. Again the 
increase in the preconsolidation pressure is due to the higher density before loading and hardening of soil material as suction increases. However, the yield states of 30B-S0.05-Lo and 30B-S0.1-Lo tests were achieved immediately when the suction was reduced from 5000 and $3500 \mathrm{kPa}$ to 50 and $100 \mathrm{kPa}$, respectively. The results of 30B-S4.3-Lo, 30B-S10-Lo, and 30B-S39-Lo tests show that the unsaturated preconsolidation pressure increased from $100 \mathrm{kPa}$ to $800 \mathrm{kPa}$ as the constant suction increased from $4300 \mathrm{kPa}$ to $39000 \mathrm{kPa}$. Moreover, Figure (17a) shows that the normal consolidated (yield) paths for both 30B-S10-Lo and 30B-S39-Lo tests are the same and the difference in the preconsolidation pressure is due to difference in the initial density. In other words, the results show that, for range of void ratio from 1.44 to 1.5 , the unsaturated preconsolidation pressure remains almost constant when the suction was changed from $4300 \mathrm{kPa}$ to $10000 \mathrm{kPa}$. The slopes of the unsaturated over consolidated path in all tests were closed to the slope of saturated over consolidated path $\left(C_{r}\right)$, while the slopes of the unsaturated normal consolidated (yield) state are higher than the slope of saturated NCL. The specimen of 30BS0.05-Lo test, Figure (12), had initially $5000 \mathrm{kPa}$ suction (point A), and then the suction was reduced to $50 \mathrm{kPa}$ under seating load (point B) which caused an increase of the gravimetric water content from 0.85 to 0.205 (point C), Figure (12b), and reduction in void ratio from 1.56 to 1.04 , Figure (12c). While the initial suction for 30BS0.1-Lo test, Figure (13), was $3500 \mathrm{kPa}$ (point A), then it was reduced to $100 \mathrm{kPa}$ under seating load (point $\mathrm{B}$ ) which caused reduction in the gravimetric water content from 0.1005 to 0.190 (point C), Figure (13b), and reduction in void ration from 1.6 to 1.06 , Figure (13c). The applied constant suction values of the other tests of this group (30B-S10-Lo, 30B-S4.3-Lo, and 30B-S39-Lo) were equaled to the initial suction. The gravimetric water content values remain almost unchanged during the yield state for high suction value ( $>4300 \mathrm{kPa}$ ), whereas the gravimetric water content decreased slightly in case of $50 \mathrm{kPa}$ and $100 \mathrm{kPa}$ constant suction conditions, Figure $(17 \mathrm{c})$. The results show that all the tests, during yield state had gravimetric water content-suction relationship follows the wetting path of SWCC.

The observed behavior, the slope of the unsaturated NCL is higher than the slope of saturated NCL, is similar to the results of ([4]; [5]; [6]; [7]; [8]; [9]; [10]; [11]; [12]; [13]; [14]; [15]; [16] and [17]). This behavior confirms the assumption of some unsaturated soil models (e. g. [5]; [7]; [13 and [18]), while it disagrees with other unsaturated soil models, where they are assumed that the slope of the unsaturated NCL is lower than the slope of saturated NCL (e. g. [19] and [20]).

Reference [21] pointed out that the apparent preconsolidation pressure of the $50 \%$ bentonite-sand mixture specimens generally increases with increasing suction indicating that the material hardened as suction increases. This behavior is generally similar to the behavior of tested bentonite-sand mixtures (30B) in this study. Reference [22] presented results showing that during the compression process at constant soil suction for an unsaturated soil, the degree of the saturation always increases with an increment of net vertical stress. Reference [14]cited that the contours of constant suction NCLs for suctions between 10 and $100 \mathrm{kPa}$ appear to be slightly curved and converge towards the fully saturated (zero suction) NCL at high vertical stresses. But the NCLs for higher suction showed straight line behavior. It is expected that the NCLs for higher suction would also converge toward the fully saturated NCL if the samples are loaded to high enough net stresses. Moreover, his results show that all the contours of constant suction NCLs have a slope larger than the saturated NCL. The behavior of soil in the work of Reference [14] is very close to the observed behavior of tested bentonite-sand mixtures in this study.

\section{Conclusions}

Regarding to the results of experimental program for a mixture of 30\% Calcigel bentonite and $70 \%$ Haider sand (30B) with two different initial states (slurry and loose) and wide range of net stresses under different values of constant suction used in study to examine the volume change behavior of Bentonite-Sand mixture under constant suction condition, the following points can be achieved:

1. The results of first group (initially slurry state) show that once the suction was applied the compressibility of the specimens in this group followed the isotropic NCL up to $255 \mathrm{kPa}$ suction. Subsequently, the slope of compression curve decreased. The results of increasing suction for initially slurry state show that the slope of compression lines became near to zero for suction higher than $600 \mathrm{kPa}$. Moreover, when applied suction is lower than the air-entry value, $s_{a e v}$, the soil behaviors as the saturated soil. Therefore, the effective stress equation can be applied.

2. The results of second group (initially loose state) show that the unsaturated preconsolidation pressure increases as the constant suction increases.

3. The position and the slope of NCL's depend on both net stress and suction.

4. For low suction value the NCL has void ratio lower than the saturated NCL (associated with flatter slope than the saturated NCL).

5. For higher suction value the NCL has void ratio higher than the saturated NCL (associated with steeper slope than the saturated NCL).

\section{Acknowledgment}

The first author would like to acknowledge the financial support for this research provided by Deutsch Akademischer Austausch Dienst, DAAD (German Academic Exchange Service).. 


\section{References}

1. Swedish Nuclear Fuel and Waste Management Company, "Final storage of spent nuclear fuelKBS-3, III barriers". Swedish Nuclear Fuel Supply Company, Division KBS Technical Report, 1992: 9:1-16:12.

2. JNC, H12: Project to establish the scientific and technical basis for HWL disposal in Japan. Supporting Report 2. "Repository design and engineering technology\{“, JNC TN1410 2000003. Japan Nuclear Cycle Development Institute, Tokai, Japan. 2000.

3. Brookins D., "Geochemical aspects of radioactive waste disposal". Springer-Verlag, 1984: 267278

4. Maswoswe, J., "Stress path for a compacted soil during collapse due to wetting". PhD thesis, Imperial College, London. 1985.

5. Josa, A., Balmaceda, A., Gens, A., and Alonso, E.E., "An elasto-plastic model for partially saturated soils exhibiting a maximum of collapse". Proc. 3rd Int. Conference Computational Plasticity, Barcelona, 1: 1992: 815-826.

6. Sivakumar, V., "A critical state framework for unsaturated soil". PhD thesis, University of Sheffield, UK. 1993.

7. Wheeler, S.J. and Sivakumar, V., "An elastoplastic critical state framework for unsaturated soils". Géotechnique, 45 (1), 1995: 35-53.

8. Wheeler, S. J., and Karube, D., "Constitutive Modelling". Proc. 1st Int. Conf. Unsaturated Soils, Paris, France, 1996: 1323-1356.

9. Sharma, R. S., "Mechanical behaviour of unsaturated highly expansive clays". PhD thesis, University of Oxford, UK. 1998.

10. Matsuoka, H., Sun, D., Kogane, A., Fukuzawa, N., and Ichihara, W., "Stress-strain behaviour of unsaturated soil in true triaxial tests". Canadian Geotechnical Journal, 39, 2002: 603-619.

11. Wheeler, S. J., Gallipoli, D., and Karstunen, M.," Comments on use of the Barcelona Basic Model for unsaturated soils". International Journal Numer. Anal. Meth. Geomech., 26, 2002:1561-1571.

12. Gallipoli, D., Gens, A., Sharma, R. and Vaunat, J., " An elasto-plastic model for unsaturated soil incorporating the effects of suction and degree of saturation on mechanical behaviour". Géotechnique, 53, No. 1, 2003: 123-135

13. Georgiadis, K., " Development, implementation and application of partially saturated soil models in FE analysis". Ph.D. thesis, Imperial College of Science, Tech. \& Medicine, Uni. of London. 2003.

14. Jotisankasa, A., "Collapse behaviour of compacted silty clay". Ph.D. thesis, Imperial College of Science, Technology and Medicine, University of London. 2005.
15. Casini, F., Vassallo, R. , Mancuso, C. and Desideri, A., "Interpretation of the behavior of compacted soils using Cam-clay extended to unsaturated conditions". $2^{\text {nd }}$ Int. Conference Mech. of Unsaturated Soil. Weimar, Germany, 7-9 March, 2007.

16. Benatti, J.C.B., Miguel, M.G., Rodrigues, R.A., and Vilar, O.M., " Collapsibility study for tropical soil profile using oedometric tests with controlled suction". $5^{\text {th }}$ Int. Conf. of Unsaturated Soils-Alonso \& Gens (eds), Barcelona, Spain,68 Sep 2010: 193-198.

17. Al-Badran, Yasir M. H., "Volumetric yielding behaviour of unsaturated fine-grained soils". PhD Dissertation. Faculty of Civil and Env. Eng., Ruhr-Universität Bochum, Germany. 2011.

18. Gallipoli, D., Wheeler, S. J. and Karstunen, M., "Modelling the variation of degree of saturation in a deformable unsaturated soil". Géotechnique, 53, No. 2. 2003: 105-112

19. Alonso, E. E., Gens, A. and Josa, A., "A constitutive model for partially saturated soils". Géotechnique, 40 (3), 1990: 405-430.

20. Kohgo, Y., Nakano, M., and Miyazaki, T., "Theoretical aspects of constitutive modeling for unsaturated soils". Soil Mech. Found. Eng. (Engl. Transl.), 33(4): 1993: 49-63.

21. Agus, S.S., "An experimental study on hydromechanical characteristics of compacted bentonite-sand mixtures". PhD Diss. Faculty of Civil Eng., Bauhaus-Universität Weimar, Germany. 2005.

22. Pham Q.H. and Fredlund, D., "A volume-mass constitutive model for unsaturated soils". Proc. Of the $58^{\text {th }}$ Canadian Geotechnical Conf., Saskatchewan, Canada. V. 2. 2005.

23. Cerato A.B. and Lutenegger A.J., " Determination of surface area of fine-grained soils by the ethylene glycol monoethyl ether (EGME) method". Geotechnical Testing Journal, ASTM, 25(3), 2002: 315-321.

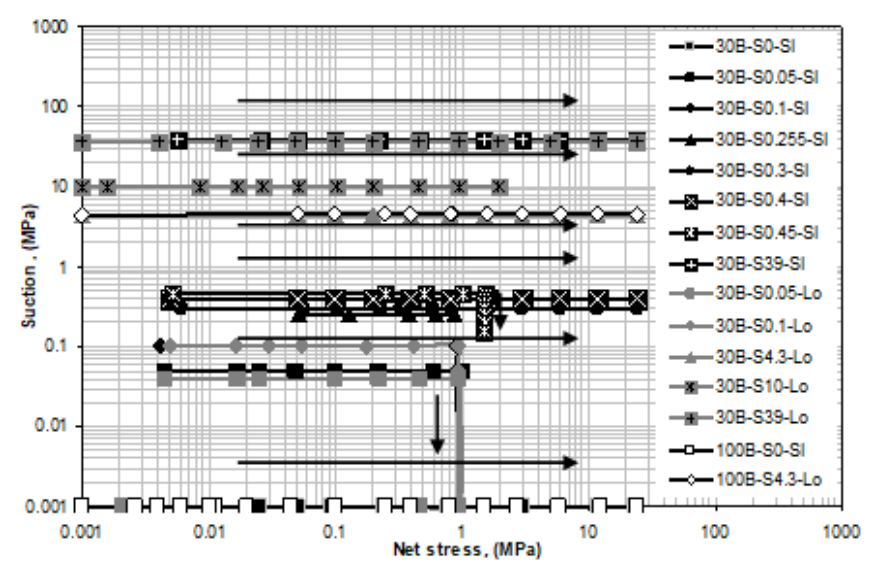

Fig. 1. Stress paths of constant suction tests for 30B soil. 

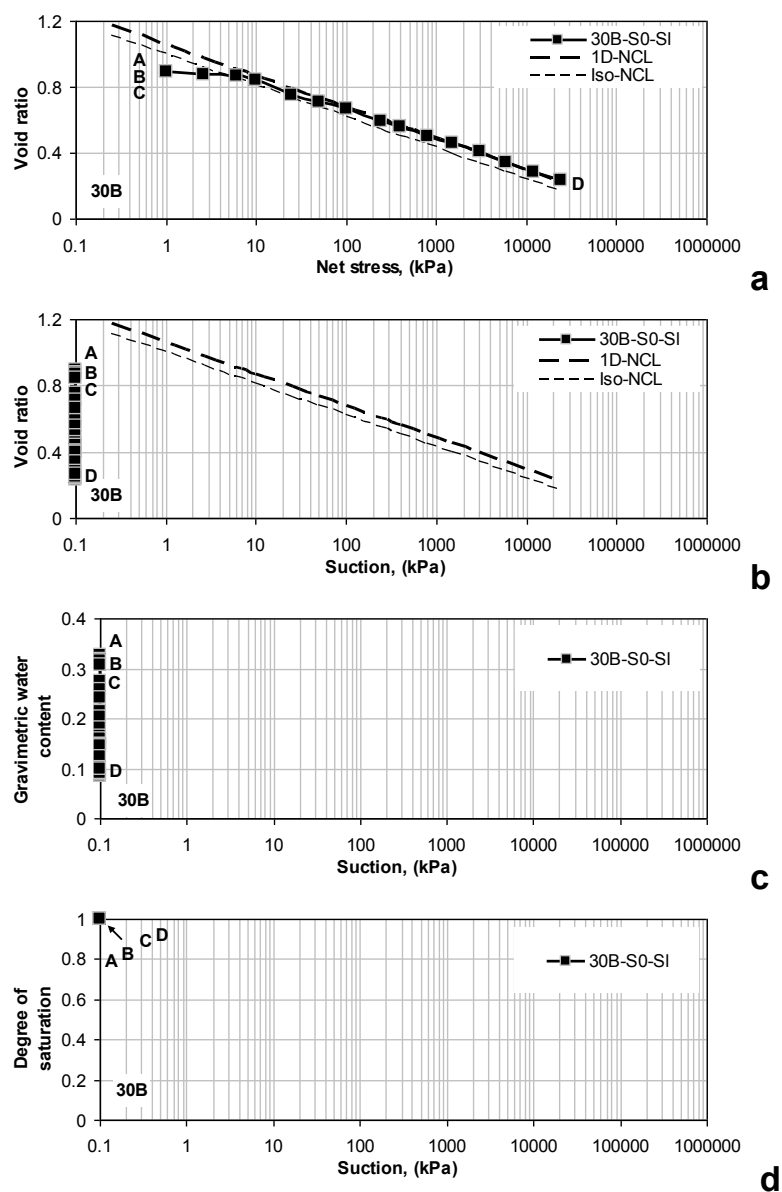

Fig. 2. Void ratio, gravimetric water content, and degree of saturation results of constant suction $=0 \mathrm{kPa}$ condition, saturated, (for log-scale of suction it is given as $0.1 \mathrm{kPa}$ ) for initially slurry $30 \mathrm{~B}$ soil.
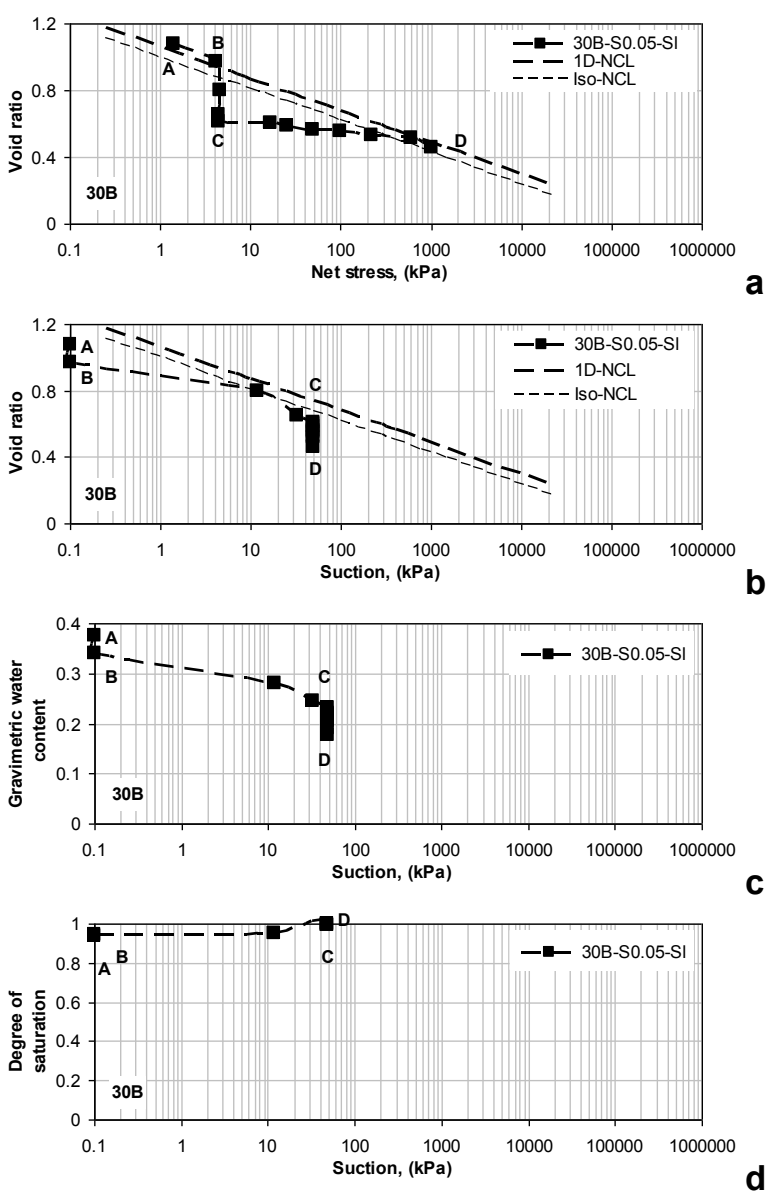

Fig. 3. Void ratio, gravimetric water content, and degree of saturation results of constant suction $=50 \mathrm{kPa}$ condition for initially slurry $30 \mathrm{~B}$ soil. 

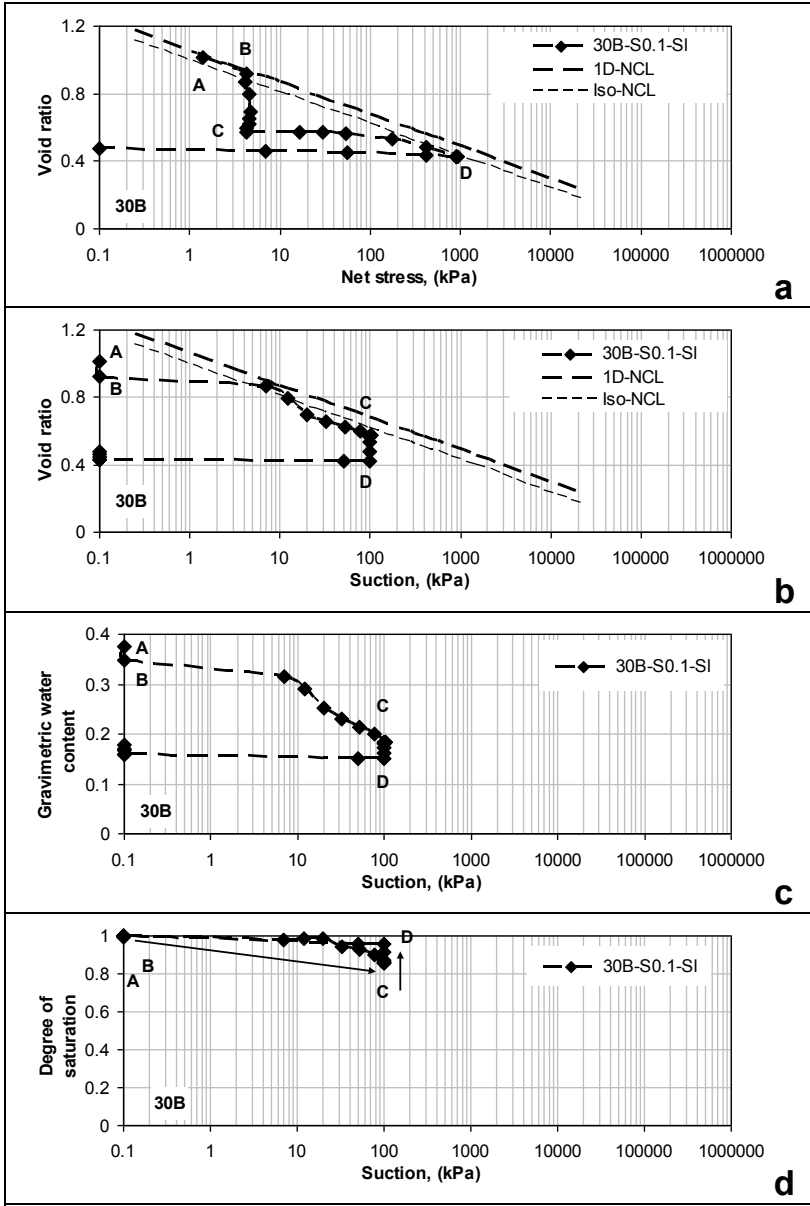

Fig. 4. Void ratio, gravimetric water content, and degree of saturation results of constant suction $=100 \mathrm{kPa}$ condition for initially slurry $30 \mathrm{~B}$ soil.
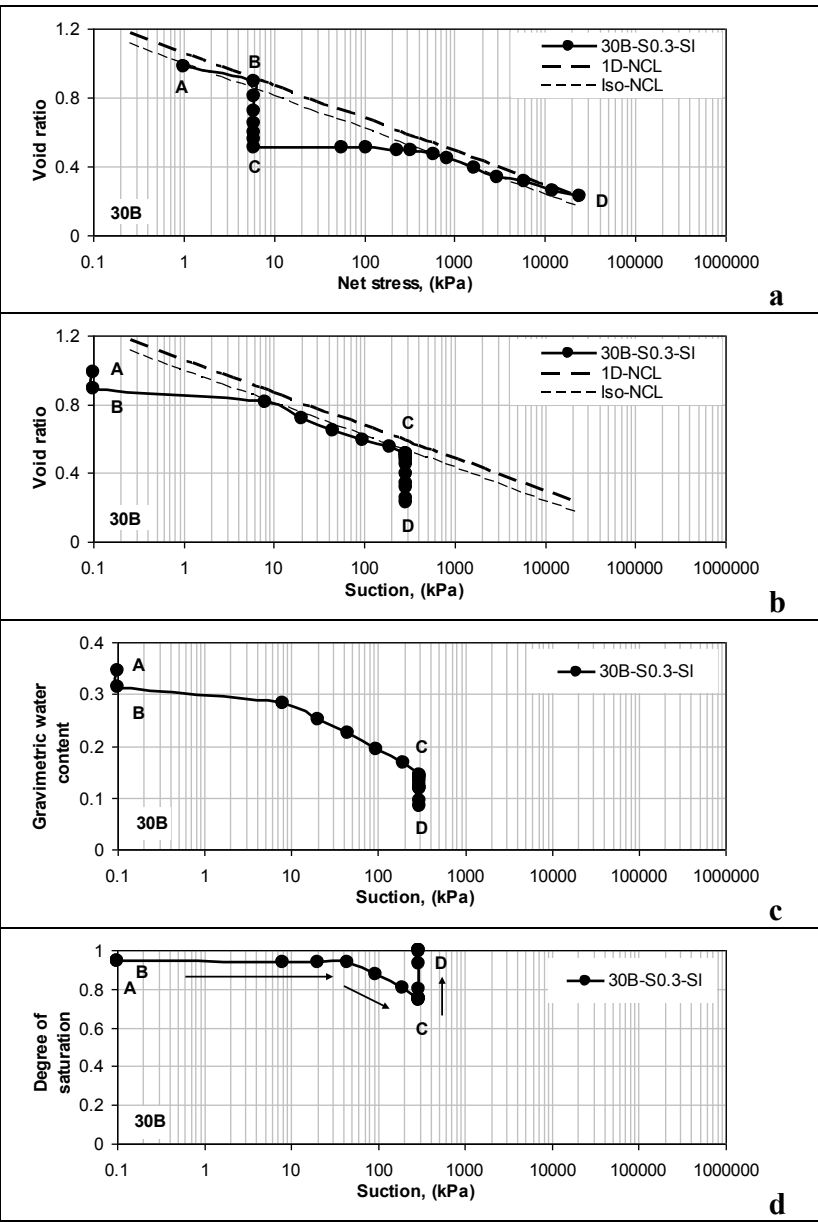

Fig. 5. Void ratio, gravimetric water content, and degree of saturation results of constant suction $=255 \mathrm{kPa}$ condition for initially slurry $30 \mathrm{~B}$ soil. 

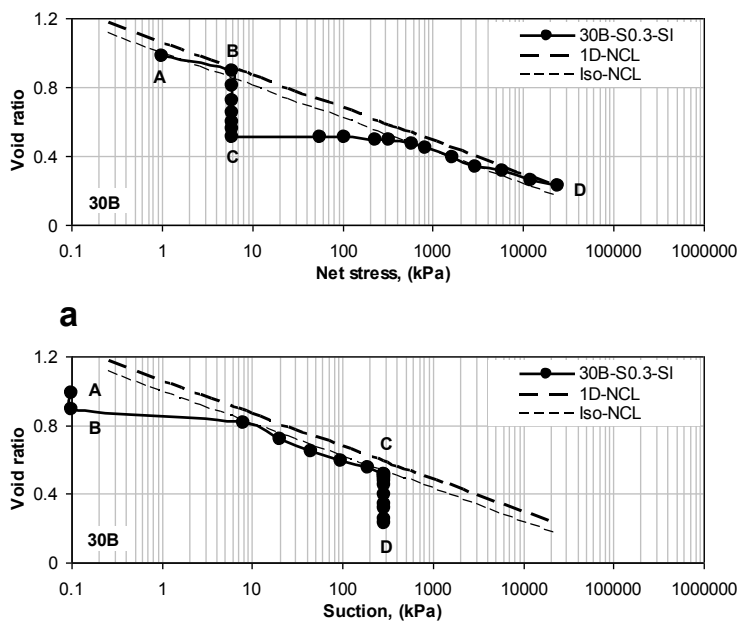

b

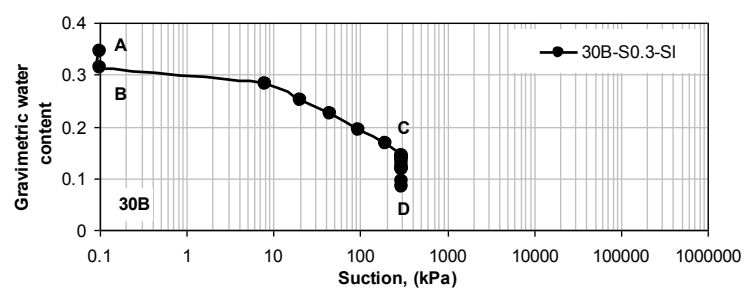

c

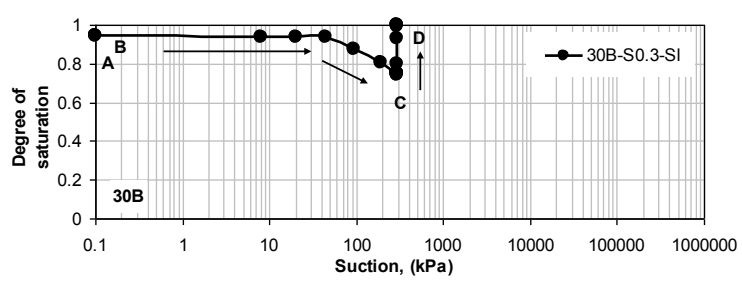

d

Fig. 6. Void ratio, gravimetric water content, and degree of saturation results of constant suction $=300 \mathrm{kPa}$ condition for initially slurry $30 \mathrm{~B}$ soil.
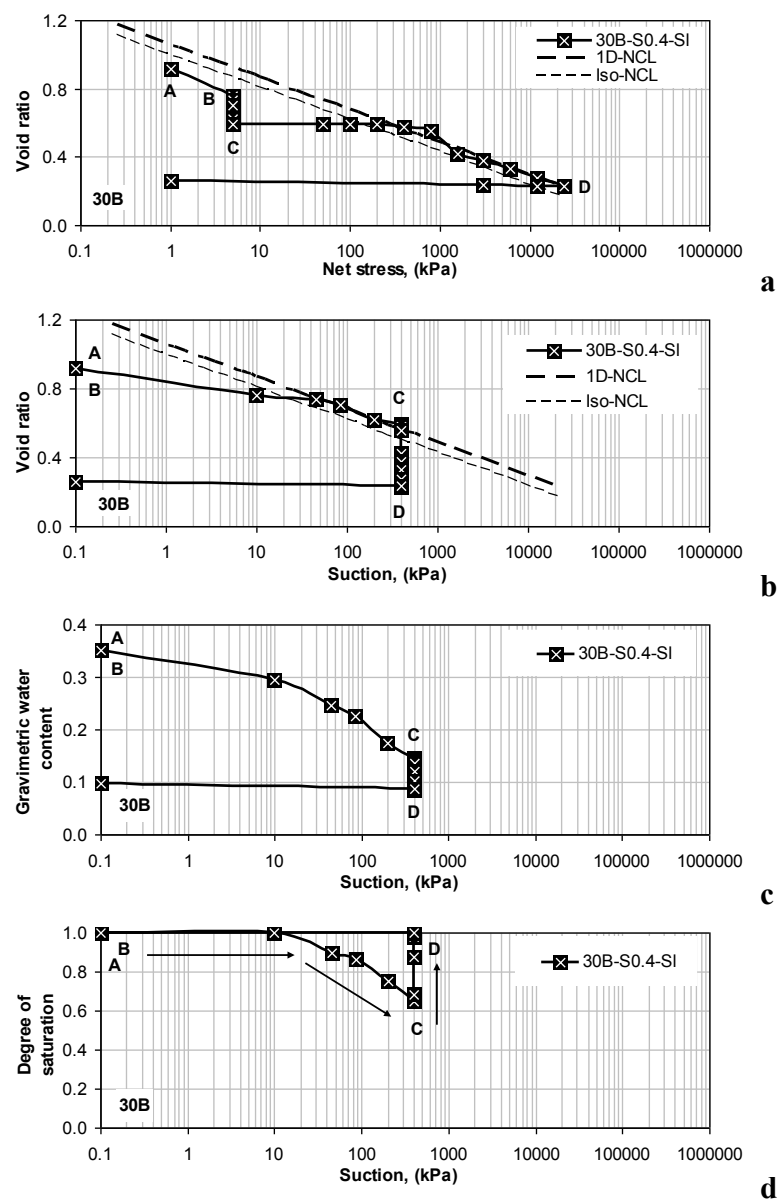

Fig. 7. Void ratio, gravimetric water content, and degree of saturation results of constant suction $=400 \mathrm{kPa}$ condition for initially slurry $30 \mathrm{~B}$ soil. 


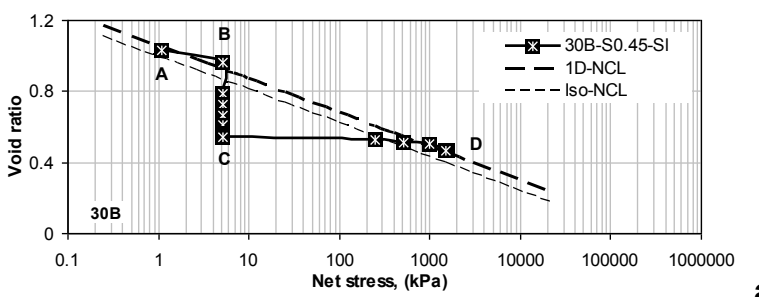

a

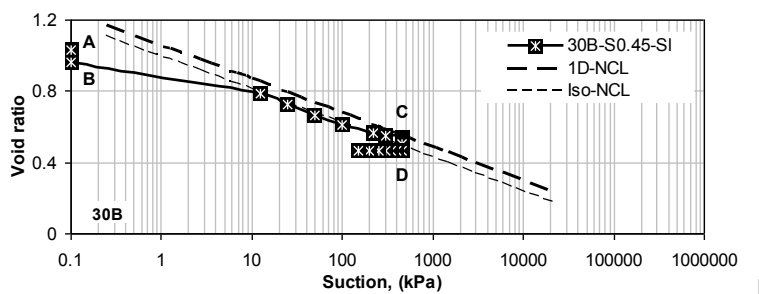

b
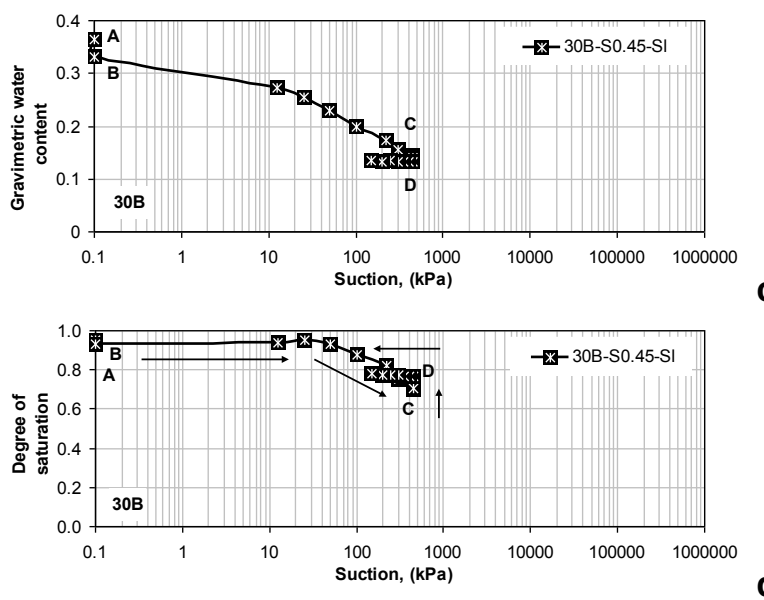

Fig. 8. Void ratio, gravimetric water content, and degree of saturation results of constant suction $=450 \mathrm{kPa}$ condition for initially slurry $30 \mathrm{~B}$ soil.
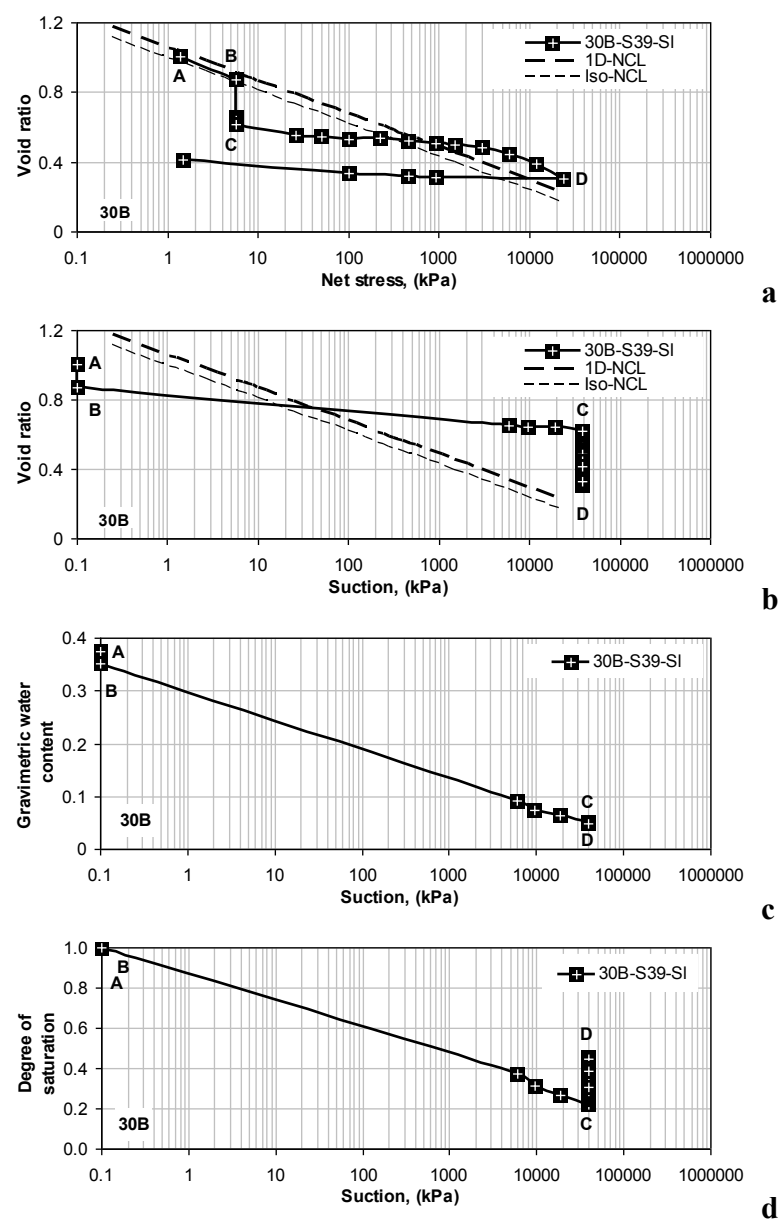

Fig. 9. Void ratio, gravimetric water content, and degree of saturation results of constant suction $=3900 \mathrm{kPa}$ condition for initially slurry $30 \mathrm{~B}$ soil. 

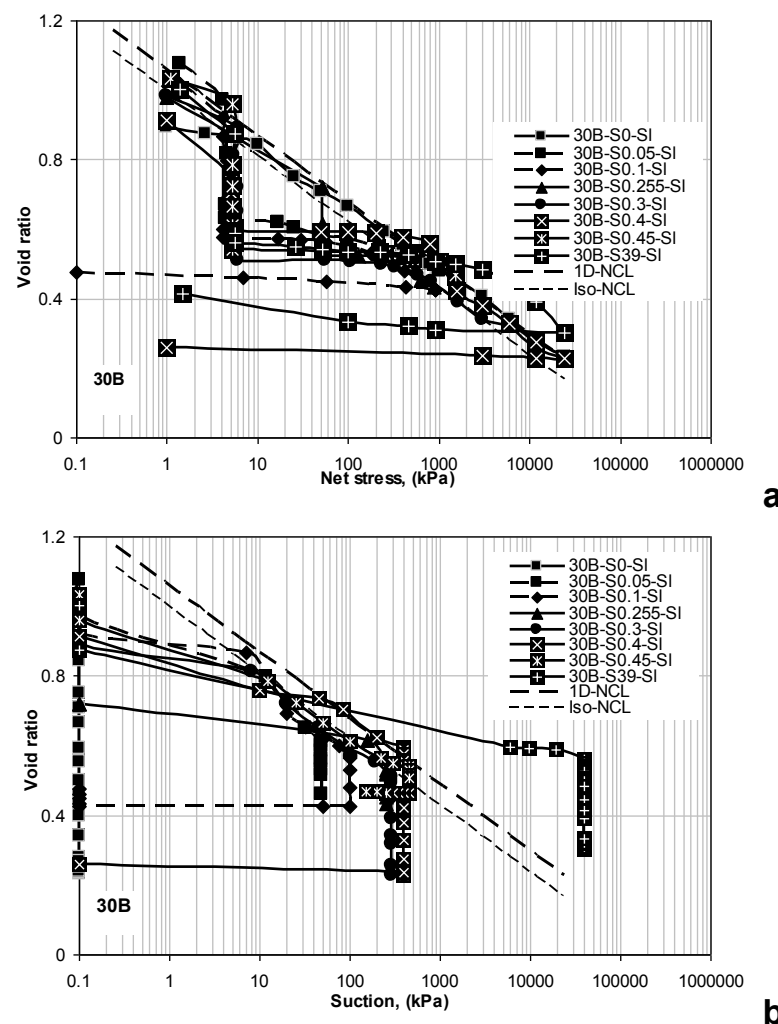

Fig. 10-1. Void ratio, gravimetric water content, and degree of saturation results of all constant suction condition for initially slurry $30 \mathrm{~B}$ soil.
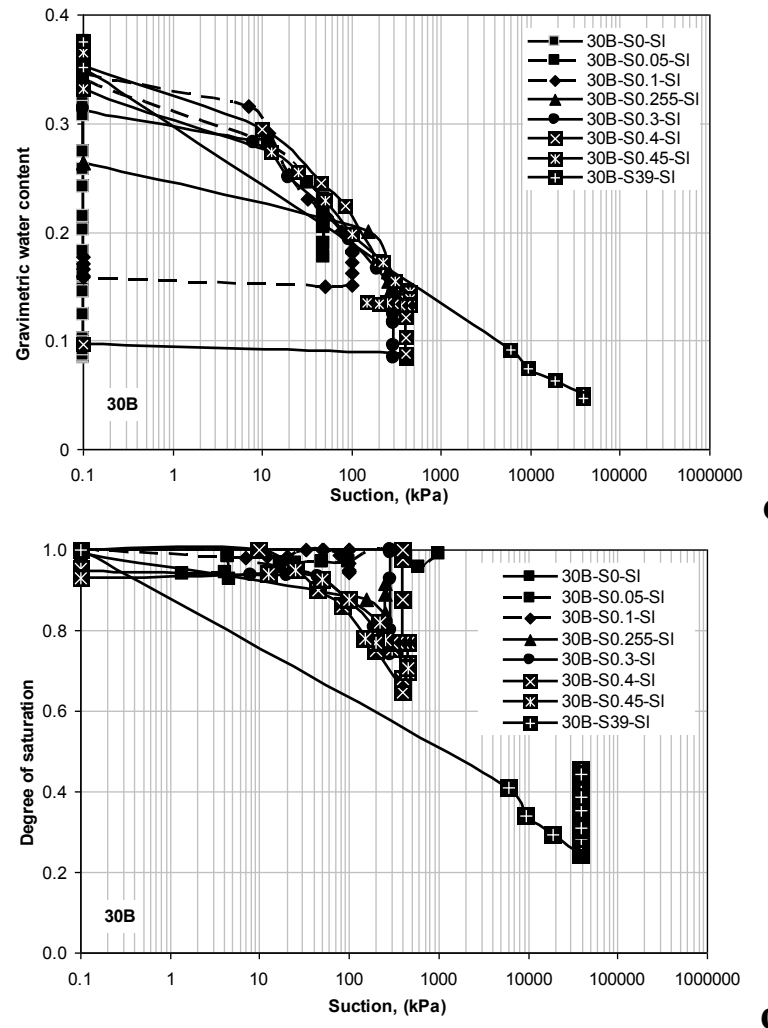

Fig. 10-2. Void ratio, gravimetric water content, and degree of saturation results of all constant suction condition for initially slurry $30 \mathrm{~B}$ soil.
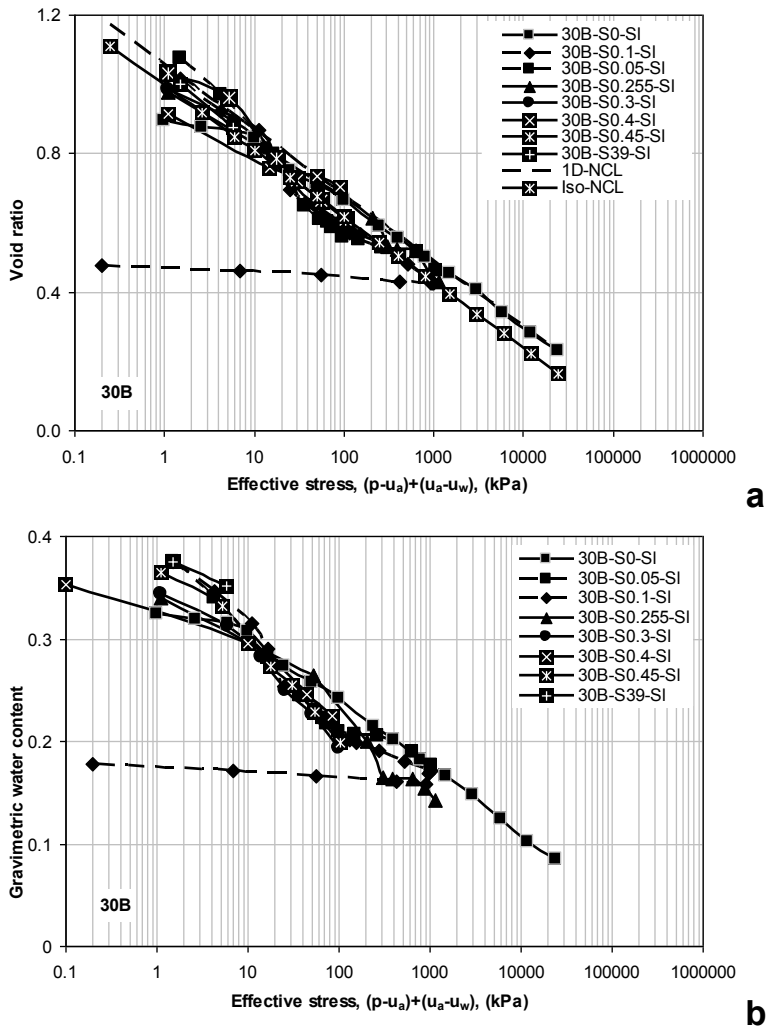

Fig. 11. Void ratio and gravimetric water content verses effective stress relationships for saturation zone of all constant suction condition for initially slurry $30 \mathrm{~B}$ soil. 

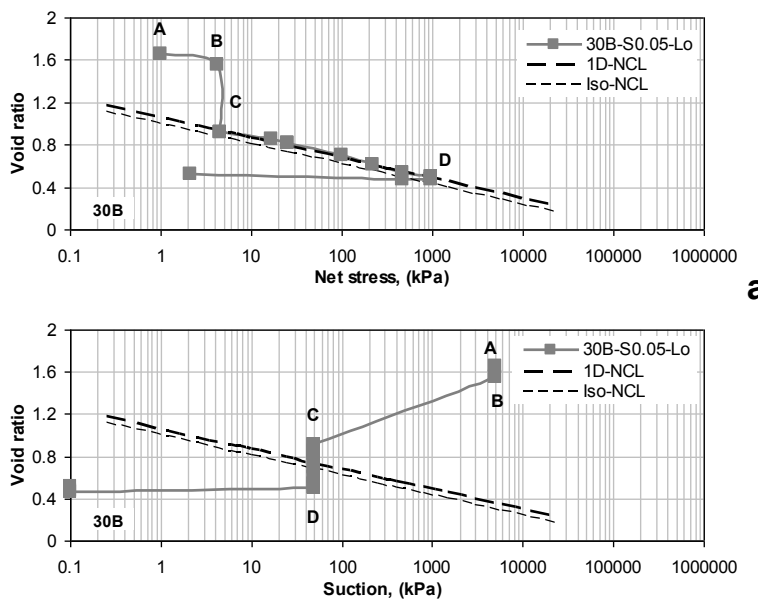

b

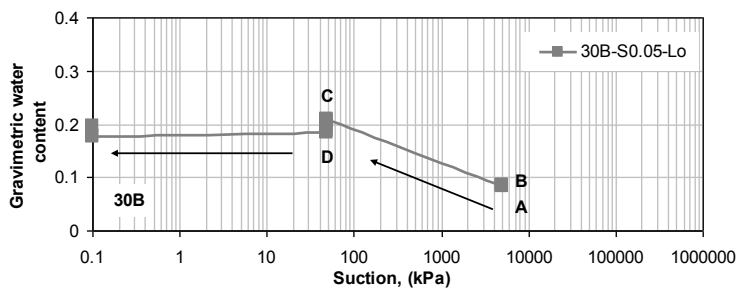

C

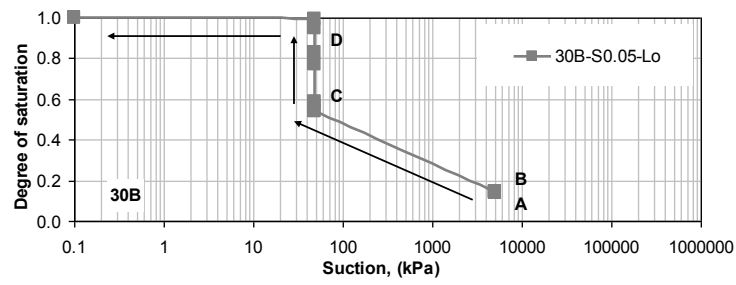

d

Fig. 12. Void ratio, gravimetric water content, and degree of saturation results of constant suction $=50 \mathrm{kPa}$ condition for initially loose $30 \mathrm{~B}$ soil.
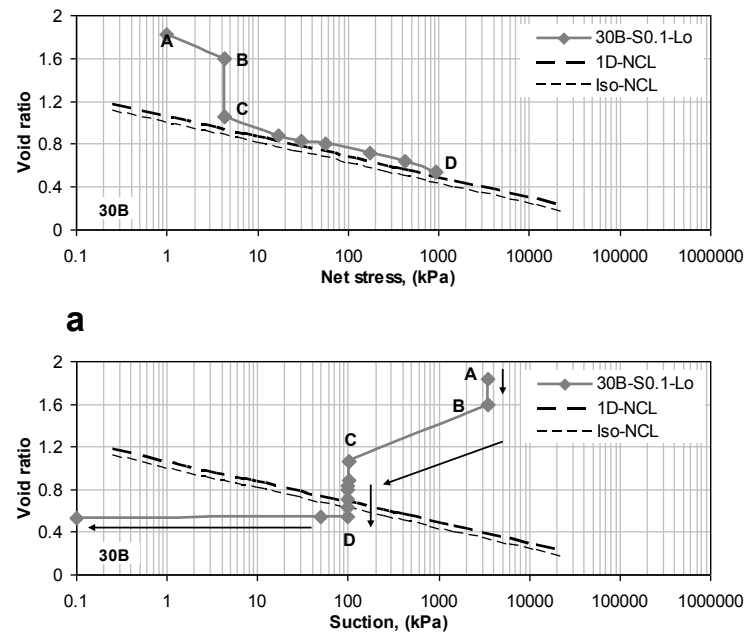

b

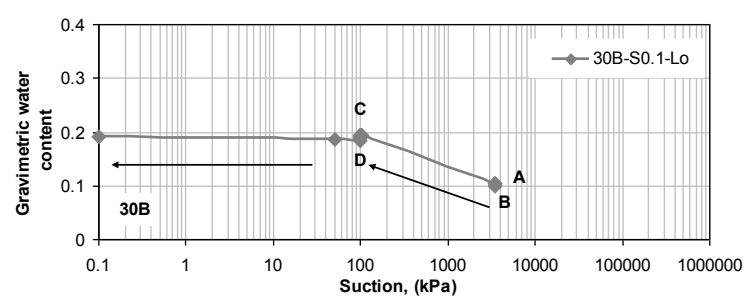

C

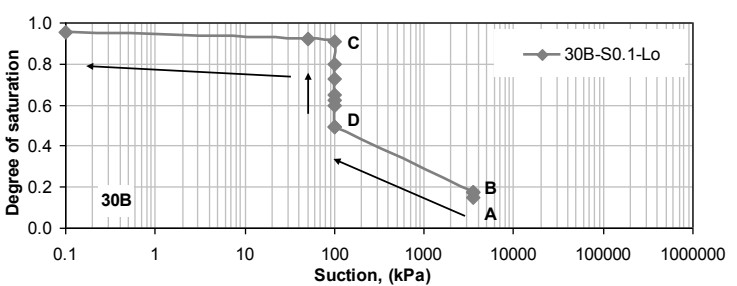

d

Fig. 13. Void ratio, gravimetric water content, and degree of saturation results of constant suction $=100 \mathrm{kPa}$ condition for initially loose $30 \mathrm{~B}$ soil. 


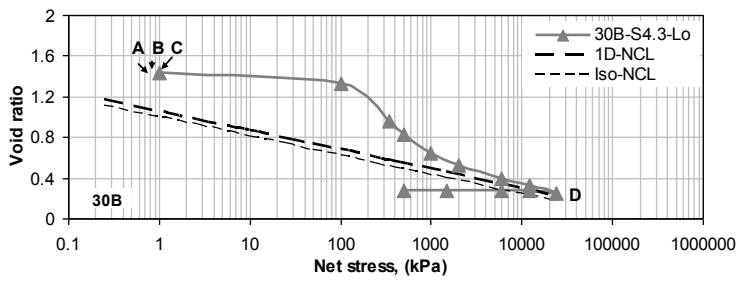

a

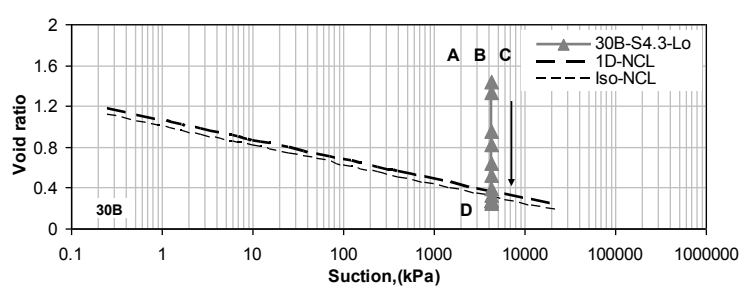

b

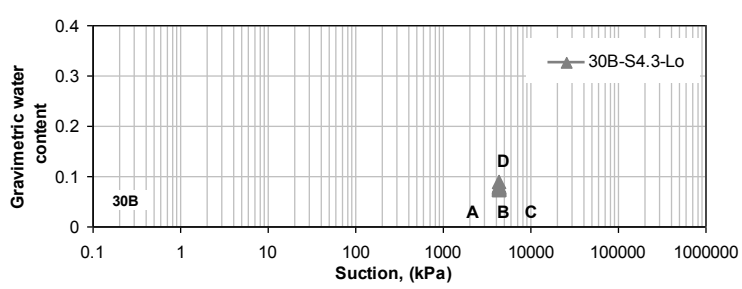

C

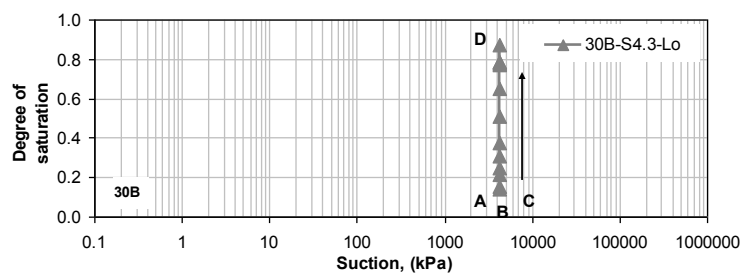

d

Fig. 14. Void ratio, gravimetric water content, and degree of saturation results of constant suction $=4300 \mathrm{kPa}$ condition for initially loose 30B soil.
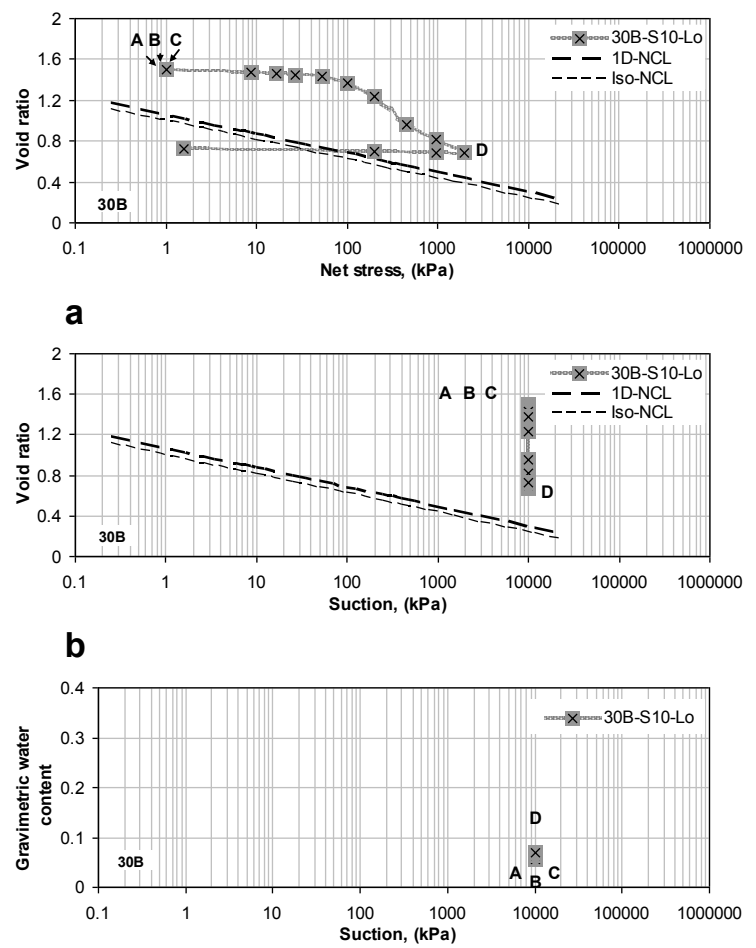

C

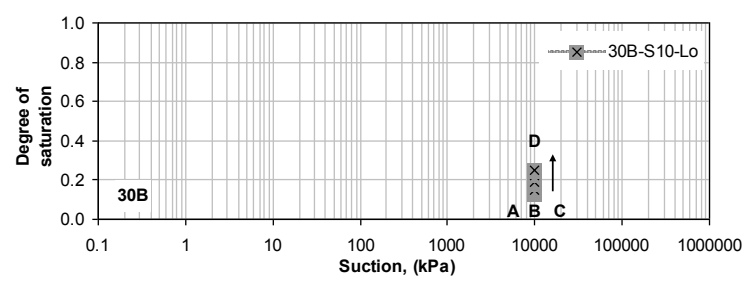

d

Fig. 15. Void ratio, gravimetric water content, and degree of saturation results of constant suction $=10000 \mathrm{kPa}$ condition for initially loose 30B soil. 

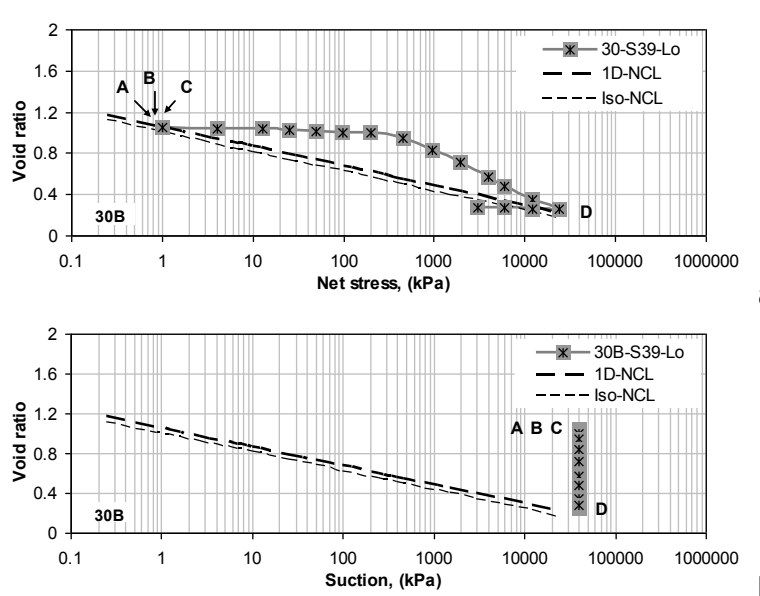

b
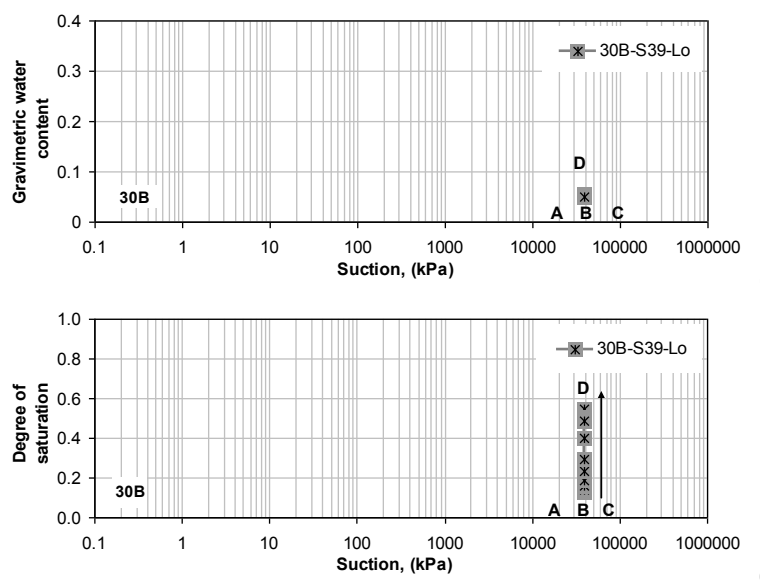

C

Fig. 16. Void ratio, gravimetric water content, and degree of saturation results of constant suction $=39000 \mathrm{kPa}$ condition for initially loose $30 \mathrm{~B}$ soil.
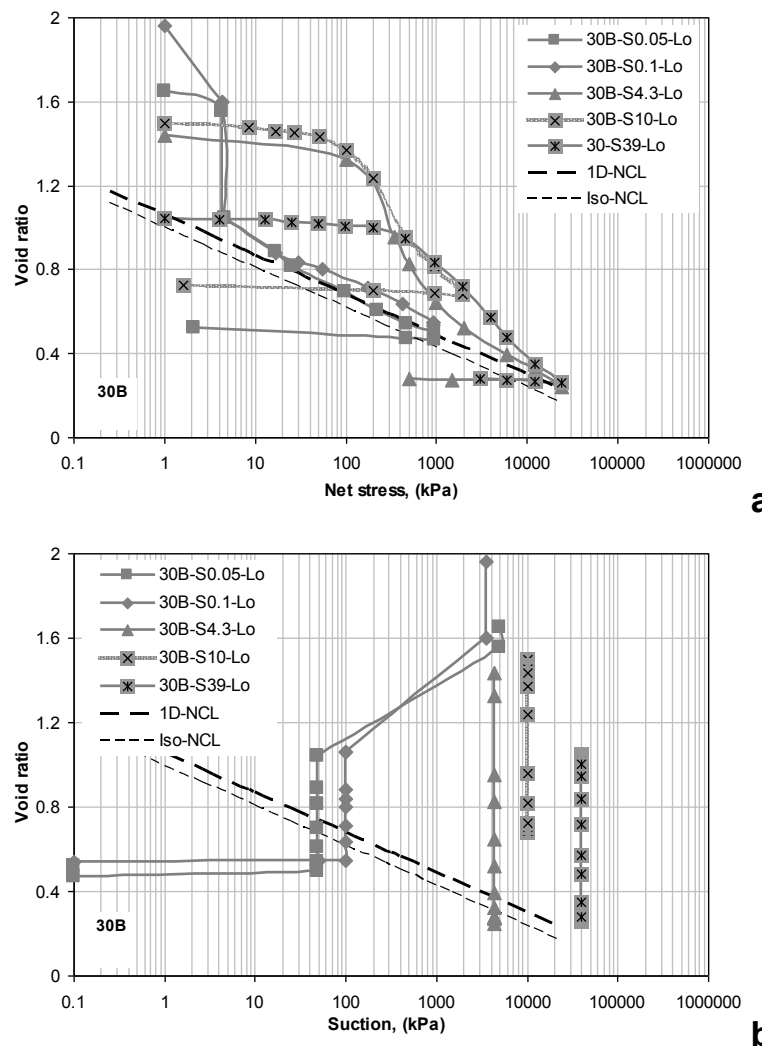

Fig. 17-1. Void ratio, gravimetric water content, and degree of saturation results of all constant suction condition for initially loose 30B soil.
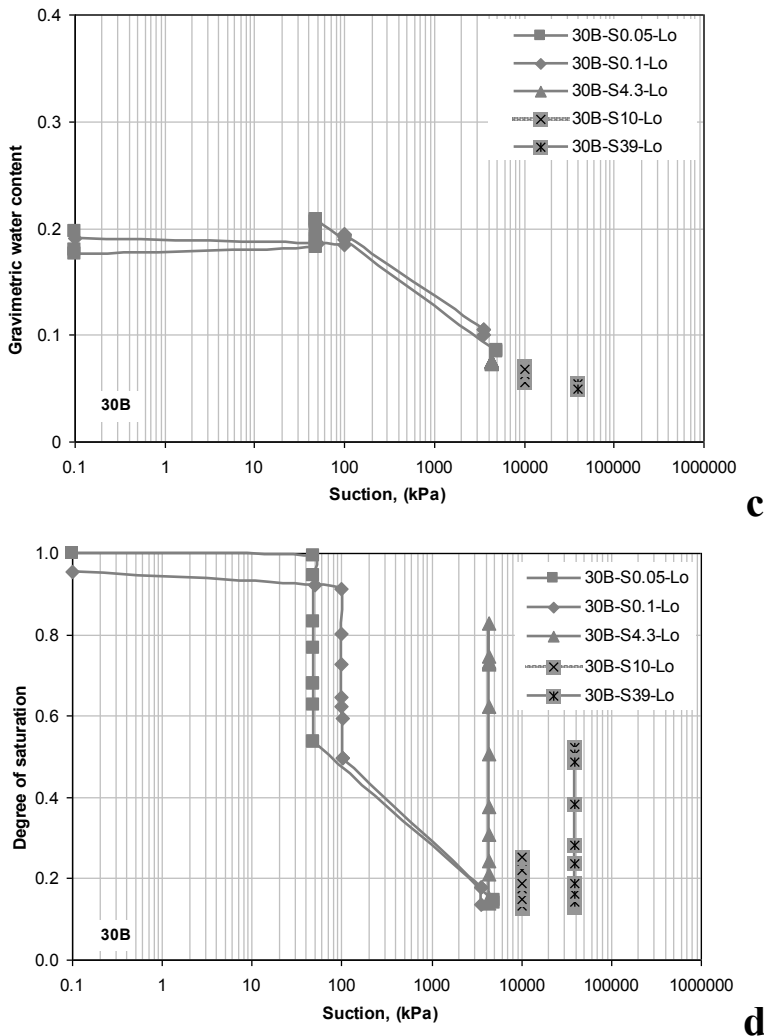

Fig. 17-2. Void ratio, gravimetric water content, and degree of saturation results of all constant suction condition for initially loose 30B soil. 